\title{
Development of Rapid Immunofilter Paper Assay for Chrysanthemum Stem Necrosis Orthotospovirus using Polyclonal Antibody Generated in Rabbits
}

\author{
Yasuhiro TOMITAKA* \\ Kyushu Okinawa Agricultural Research Center, National Agriculture and Food Research \\ Organization, Koshi, Japan
}

\begin{abstract}
A simple detection method using a rapid immunofilter paper assay was developed in this study. First, the $\mathrm{N}$ protein gene-coding region of a chrysanthemum stem necrosis orthotospovirus (CSNV) isolate collected in Japan was amplified by reverse transcription-polymerase chain reaction and introduced into the multi-cloning site of the pMAL-c5X vector. The vector was introduced into Escherichia coli (Rosetta DE3) competent cells, and ca. $75 \mathrm{kDa}$ fusion protein of CSNV-N and maltose binding protein was obtained by liquid culture. Antiserum was obtained from rabbits immunized with the fusion protein. IgG was purified from the antiserum, and its titer was determined by enzyme-linked immunosorbent assay to be approximately 200 -fold. Immunochromatograms were prepared by rapid immunofilter paper assay using the IgG. CSNV was detected in diseased plants using the immunochromatograms and red polystyrene particles at a concentration of $8 \%$.
\end{abstract}

Discipline: Agricultural Environment

Additional key words: ELISA, detection, orthotospovirus, rapid immunofilter paper assay

\section{Introduction}

Orthotospovirus (formerly referred to as tospovirus) is the species of the Orthotospovirus genus within the family Tospoviridae. Thus far, more than 30 Orthotospovirus species, including tentative species, have been reported around the world (Okuda 2016, ICTV Taxonomy, https://talk.ictvonline.org/ taxonomy/). Among them, eight have been recorded in Japan: capsicum chlorosis orthotospovirus (CaCV), chrysanthemum stem necrosis orthotospovirus (CSNV), impatiens necrotic spot orthotospovirus (INSV), iris yellow spot orthotospovirus (IYSV), lisianthus necrotic ringspot orthotospovirus, melon yellow spot orthotospovirus (MYSV), tomato spotted wilt orthotospovirus (TSWV), and watermelon silver mottle orthotospovirus (WSMoV) (Okuda 2016). Orthotospovirus is transmitted by specific thrips species such as Frankriniella occidentalis and Thrips palmi in a circulative and propagative manner (Ullman et al. 2002).

CSNV was first found in chrysanthemums in Brazil (Bezerra et al. 1999, Duarte et al. 1995). In Japan, CSNV was detected in chrysanthemums in Hiroshima Prefecture in 2006 (Okuda 2016). The virus causes severe damage not only to chrysanthemums but also to some vegetables such as tomatoes and green peppers, on which necrosis and necrotic yellowing typically appear (Kuwabara \& Sakai 2008, Matsuura et al. 2007, Momonoi et al. 2011). Moreover, the virus infection causes serious damage in infected plants and results in a yield loss (Matsuura et al. 2007). CSNV virions are spherical in shape and ca. 100 $\mathrm{nm}$ in diameter, and its genome is composed of three segments (L, M, and S) that are responsible for the expression of the following proteins: a putative cell-tocell movement protein (NSm), a nonstructural protein (NSs), a nucleocapsid protein (N), an RNA-dependent RNA polymerase (RdRP), and a precursor of surface glycoproteins $\left(\mathrm{G}_{\mathrm{N}} / \mathrm{G}_{\mathrm{C}}\right)$ cleaved into $\mathrm{G}_{\mathrm{N}}$ and $\mathrm{G}_{\mathrm{C}}$ (German et al. 1992). The genomes of these three segments are encapsidated by $\mathrm{N}$ proteins encoded by $\mathrm{S}$ segments. In addition, there is a higher amount of $\mathrm{N}$ protein than other proteins in plants infected with orthotospovirus.

The most effective means of controlling plant viruses is interference in the infection cycle in the field. Thus, detection is important for management of a virus. Detection methods involving molecular and serological 
techniques have been developed and used worldwide for this purpose. Reverse transcription-polymerase chain reaction (RT-PCR) and PCR are examples of powerful and sensitive techniques used to detect plant viruses. However, conventional and simple detection methods such as enzyme-linked immunosorbent assay (ELISA), rapid immunofilter paper assay (RIPA), and dot immunoblotting assay are still used for some purposes. The antibody to CSNV is rather costly in Japan (Kuwabara et al. 2010, Fukami et al. 2014), even though it is commercially available (e.g., Nano Diagnostics, AR, USA). There is also great demand for the development of an antibody-based CSNV detection method that can quickly and easily detect viruses. However, such a method has yet to be developed in Japan. To address the issues outlined above, we produced a polyclonal antibody for CSNV in rabbits and developed RIPA for CSNV in the present study.

\section{Materials and methods}

\section{Viral isolate}

CSNV-infected tomato plants (with unidentified cultivar) were collected in Chiba Prefecture, Japan. Infected leaves were ground with a mortar and pestle in $0.05 \mathrm{M}$ phosphate buffer (PB) containing $10 \mathrm{mM}$ sodium sulfite. The sap was inoculated into Petunia $\times$ hybrida and single local lesion isolation was conducted three times. Finally, the viral isolate was propagated in Nicotiana benthamiana. The infected leaves were collected 10 days after inoculation and stored at $-80^{\circ} \mathrm{C}$.

\section{Construction of expression vector of fusion protein}

The expression vector was constructed by using an In-Fusion HD Cloning Kit (TAKARA). First, total RNA was extracted from the diseased $N$. benthamiana leaves using the RNeasy Plant Mini Kit (QIAGEN, Hilden, Germany). The extracted RNA was used as a template for RT-PCR, and the sequence region corresponding to the N gene of CSNV was amplified using the PrimeScript One Step RT-PCR Kit (TAKARA, Shiga, Japan). Sequences homologous to the pMAL-c5X vector (Promega, Tokyo, Japan) were added to the $5^{\prime}$ end of the forward and reverse primers CSNV-NF and CSNV-NR (Table 1). These primers were used for RT-PCR under the following conditions: $30 \mathrm{~min}$ at $50^{\circ} \mathrm{C}$ and $2 \mathrm{~min}$ at $94^{\circ} \mathrm{C}$ followed by 30 cycles of $30 \mathrm{~s}$ at $94^{\circ} \mathrm{C}, 30 \mathrm{~s}$ at $55^{\circ} \mathrm{C}$, and $1 \mathrm{~min}$ at $72^{\circ} \mathrm{C}$.

The partial nucleotide sequence of the pMAL-c5X vector was amplified from a plasmid, with pMAL-c5X as a template, using KOD Plus version 2 (TOYOBO, Tokyo, Japan). The forward and reverse primers used for PCR, pMAL-F, and pMAL-R were designed in the multicloning site of the pMAL-c5X vector (Table 1). PCR was conducted under the following conditions: $94^{\circ} \mathrm{C}$ for 2 min., then 35 cycles of $15 \mathrm{~s}$ at $98^{\circ} \mathrm{C}, 30 \mathrm{~s}$ at $55^{\circ} \mathrm{C}$, and 4 min. at $68^{\circ} \mathrm{C}$.

The amplified fragments were separated in $1 \%$ agarose gel electrophoresis, and fragments of the expected size were extracted using the QIAquick Gel Extraction Kit (QIAGEN). These fragments were combined using an In-Fusion HD Cloning Kit (TAKARA) and transformed into Escherichia coli competent cells, JM109 (TAKARA). All procedures were performed as per the manufacturer's instructions. We selected three independent colonies in which a sequence corresponding to the $\mathrm{N}$ protein of CSNV was inserted. Insertion of the target sequence was confirmed by sequencing using primers designed upstream and downstream of the multicloning site of the pMAL-c5X vector. Table 1 lists the primers used for sequencing (pMAL-Fseq and pMALRseq).

\section{Expression and purification of fusion protein}

To confirm the expression level of each clone's fusion protein, the three clones prepared above were introduced separately into $E$. coli Rosetta DE3 competent cells (Merck Millipore, MA, USA). The transformed $E$. coli isolates were incubated in $5 \mathrm{ml} \mathrm{LB}$ liquid medium containing Overnight Express Autoinduction System 1 (Merck Millipore) and ampicillin with shaking for $12 \mathrm{~h}$. Then, the cells were precipitated by centrifugation $(10,000 \times g, 10 \mathrm{~min})$ and the protein was extracted from

Table 1. Primers used for construction of an expression vector

\begin{tabular}{ll}
\hline \hline \multicolumn{1}{c}{ Primer } & \multicolumn{1}{c}{ Sequence $\left(5^{\prime} \text { to } 3^{\prime}\right)^{\mathrm{a}}$} \\
\hline CSNV-NF & TTCGGATCCGTCGACTTAATGGTGATGGTGATGGTGAACAAGATCTTTAGGAATAAG \\
CSNV-NR & TCCATGGGCGGCCGCATGTCTAAAGTTAAGCTTACA \\
pMAL-F & GTCGACGGATCCGAATTCCC \\
pMAL-R & GCGGCCGCCCATGGACATAT \\
pMAL-Fseq & CGCAGACTAATTCGAGCTCG \\
pMAL-Rseq & CGAAAGGCCCAGTCTTTCGA \\
\hline
\end{tabular}

a Sequences homologous with the pMAL-c5X vector and CSNV are underlined and italicized, respectively. 
the cells using BugBuster ${ }^{\circledR}$ Protein Extraction Reagent (Merck Millipore). The fusion protein, consisting of maltose binding protein (MBP) and CSNV-N protein, was then purified using amylose resin. To immunize rabbits, the fusion protein was prepared using $500 \mathrm{ml} \mathrm{LB}$ liquid medium containing Overnight Express Autoinduction System 1 (Merck Millipore) and ampicillin as per the manufacturer's instructions. Expression of the target protein was confirmed by SDS-PAGE using a Mini-PROTEAN ${ }^{\circledR}$ TGX ${ }^{\mathrm{TM}}$ Gel (BIORAD, CA, USA). Finally, the fusion protein was purified using amylose resin as per the manufacturer's instructions.

\section{Production of antiserum and purification of IgG antibody}

Two rabbits were immunized with the fusion protein to produce antiserum. The acquisition of immunity and antiserum for rabbits was conducted by ARK Resource Co., Ltd. (Kumamoto, Japan). Each rabbit was immunized three times with $0.2 \mathrm{mg}$ of the fusion protein. The IgG was purified from the obtained antiserum using Pierce Protein A (Thermo Fisher Scientific). The procedure was performed as per the manufacturer's instructions.

\section{Evaluation of IgG by ELISA}

The titer of purified IgG was evaluated by indirect ELISA. Leaves of Nicotiana tabacum cv. Samsun infected with CSNV or TSWV were ground with a mortar and pestle in $\mathrm{PB}(\mathrm{pH}=7)$ of 10 times the amount $(\mathrm{vol} / \mathrm{w})$ of the tissues. This mixture was then centrifuged $(6,000 \times g$, $10 \mathrm{~min}$.) and the supernatant was used as the antigen. Healthy N. tabacum leaves were used as a control. Purified IgG was serially diluted $(50,100,200,500$, 1,000 , and 2,000-fold dilutions) with the phosphate buffer, and then used for the following experiment. ELISA was performed according to the previously reported method (Clark \& Adams 1977, Ohki 1997). Absorbance (A405) was measured $45 \mathrm{~min}$ after the addition of $p$-nitrophenyl phosphate. Three replicates (wells) were used for each sample.

\section{Detection of CSNV using RIPA}

To develop a simple detection method using the antiCSNV-IgG, immunochromatography was performed according to the previously reported RIPA method (Gappa \& Tsuda 2015, Tsuda et al. 1992). Anti-CSNV$\operatorname{IgG}(1 \mathrm{mg} / \mathrm{ml})$ was used for following experiment. Two kinds of polystyrene particles (Thermo Scientific, USA) were used for RIPA. White-colored polystyrene particles (W050CA, $0.51 \mu \mathrm{m}$ ) was used for the solid phase, and red-colored polystyrene particles (DR1040CA, $0.39 \mu \mathrm{m}$ ) were used for the tracer. The anti-CSNV-IgG was diluted to $500 \mu \mathrm{g} / \mathrm{ml}$ with Tris-buffered saline (TBS). For coating of the IgG antibody, white and red particles were diluted to $2 \%$ concentration $(\mathrm{v} / \mathrm{v})$ and $1 \%$ concentration $(\mathrm{v} / \mathrm{v})$ with the diluted $\mathrm{IgG}$, respectively. The mixtures were incubated at $37^{\circ} \mathrm{C}$ for $2 \mathrm{~h}$ with occasionally shaking by a vortex mixer (M\&S Instruments Inc. Japan). The particles coated with IgG were washed three times by centrifugation at $17,800 \times g$ for $10 \mathrm{~min}$. with TBS-BSA (TBS with $0.1 \%$ bovine serum albumin). The precipitates were resuspended in TBS-BSA ( $2 \%$ for white particles and $1 \%$ for red particles). White particles coated with $\operatorname{IgG}$ were applied approximately $1.5 \mathrm{~cm}$ from the lower end of glass filter paper (GF/A, Whatman, Kanagawa, Japan). To determine a suitable concentration of red-colored polystyrene particles (Thermo Scientific), the IgG was sensitized with $5 \%$ and $8 \%$ red-colored polystyrene particles. In this experiment, in the case of the immobilized white particles coated with $\operatorname{IgG}$ present as a solid in a line on the surface of the strip, the virus reacted with IgG-coated red particles, and moved up of the strip. Thereafter, the virus on dyed particles is sandwiched with immobilized white particles coated with IgG and forms a red line.

CSNV-infected tobacco (Nicotiana tabacum cv. Samsun), chrysanthemum (Chrysanthemum morifolium cv. unidentified), and tomato (Solanum lycopersicum cv. Momotaro) leaves were ground with 10 times the amount $(\mathrm{vol} / \mathrm{w})$ of phosphate buffer $(\mathrm{pH}=7)$ with a mortar and pestle, and the mixture was used for detection. TSWVinfected tobacco leaves were used as a control. We judged the positive and negative reactions about 15-30 min. later after the strip was dipped into the solution containing the red particles. When a red color line appeared on the strip, we assessed the sample as positive. The test was conducted twice.

\section{Results and discussion}

In this study, CSNV antiserum was produced in rabbits and the IgG purified from the antiserum was used to develop a simple CSNV detection method. Polyclonal or monoclonal antibodies against orthotospoviruses have been conventionally produced using purified nucleocapsids or artificially expressed proteins (Feldhoff et al. 1997, Vaira et al. 1996). Obtaining these antibodies has sometimes been difficult, however, as the fusion protein is only presented in small amounts. In this study, the $\mathrm{N}$ protein of CSNV was expressed as a fusion protein with MBP, because MBP has a relatively strong effect of preventing inclusion body formation in the cells (Guan et al. 1988). The supernatant of the centrifuged cell lysate was analyzed by SDS-PAGE, and a product of ca. $75 \mathrm{kDa}$, 
which appeared to be a fusion protein, was observed (Fig. 1, lanes 1-3). Furthermore, when the solution was purified with amylose resin, a large amount of protein of ca. 75 $\mathrm{kDa}$ was detected as a single band by SDS-PAGE analysis (Fig. 1, lane 4). The putative molecular masses of MBP and $\mathrm{N}$ protein are approximately $42.5 \mathrm{kDa}$ and $31 \mathrm{kDa}$, respectively, indicating that the single band observed by SDS-PAGE analysis was a fusion protein of MBP and N protein. Thus, the data indicate that the $\mathrm{N}$ protein of CSNV was expressed as a soluble fusion protein with MBP, and that this method is useful for the expression of CSNV-N protein. Finally, we obtained approximately 3 $\mathrm{mg}$ of fusion protein from $500 \mathrm{ml}$ of the culture (data not shown). The results suggest that this method may also be useful for the expression of $\mathrm{N}$ protein from other orthotospovirus species such as MYSV and $\mathrm{CaCV}$ occurring in East Asian countries.

Antiserum was obtained by immunizing rabbits three times in total, each with $0.2 \mathrm{mg}$ of the fusion

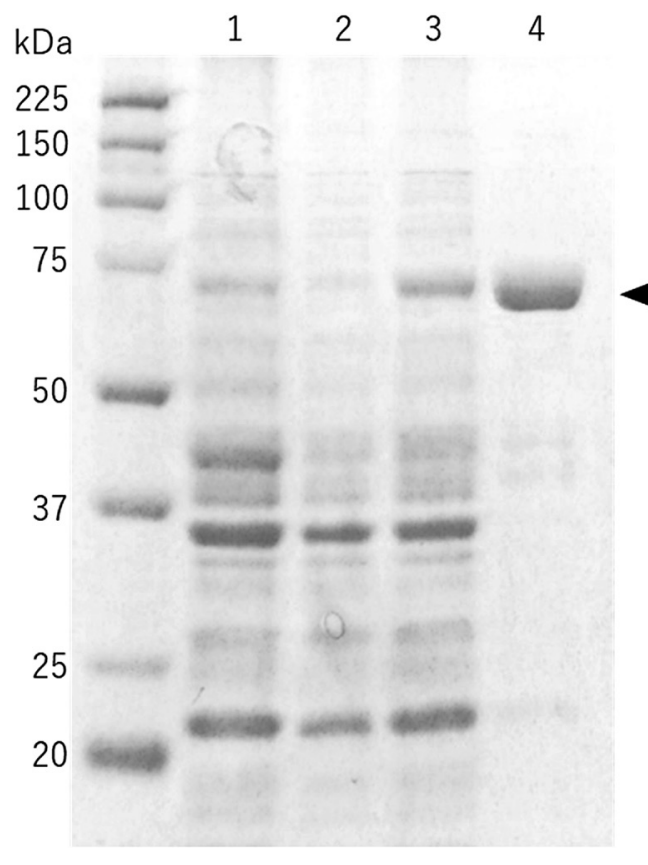

Fig. 1. Electrophoresis of fusion protein consisting of chrysanthemum stem necrosis orthotospovirus- $\mathrm{N}$ protein and maltose binding protein by SDS-PAGE analysis

Lanes 1-3 show the crude extracts obtained from culture of three independent and different colonies of Escherichia coli (Rosetta DE3). Lane 4 shows a fusion protein sample purified from the crude extract in lane 3. Arrowhead indicates the putative fusion protein. Precision Plus Protein $^{\mathrm{TM}} \quad$ Kaleidoscope ${ }^{\mathrm{TM}} \quad$ Prestained Protein Standards (Promega) were used as a molecular weight maker. protein. The IgG antibody was then purified from the antiserum and its titer was evaluated by the indirect ELISA method using $N$. tabacum leaves infected with CSNV. CSNV was found to react significantly to antiCSNV-IgG in 50, 100, and 200-fold dilutions (Fig. 2). Conversely, anti-CSNV-IgG did not react with TSWVinfected leaves. Although the titers of antibodies produced using nucleocapsids of orthotospoviruses conventionally range from 1,000 to 500 -fold dilution (Feldhoff et al. 1997, Vaira et al. 1996), the titer of the anti-CSNV-IgG produced in the present study was relatively lower than that of these reports. Although a fusion protein of MBP and $\mathrm{N}$ protein was used as an antigen to immunize rabbits in this study, the $\mathrm{N}$ protein excluding the MBP tag may be more suitable for an antigen.

The RIPA method is an effective means of rapidly detecting plant viruses (Gappa \& Tsuda 2015, Osaki et al. 2011, Tsuda et al. 1992). IgG produced in the present study was examined for its applicability to RIPA as a means of detecting CSNV using tobacco, chrysanthemum, and tomato leaves infected with CSNV. A red line indicating a positive result was not observed when IgG was sensitized with red polystyrene particles at a concentration of 5\%. However, when IgG was sensitized with red particles at a concentration $8 \%$, a red line was clearly observed on the strip (Fig. 3). Gappa \& Tsuda (2015) showed that red particles at a concentration $8 \%$ are suitable for the detection of melon yellow spot orthotospovirus in cucumber (Cucumis sativus L.).

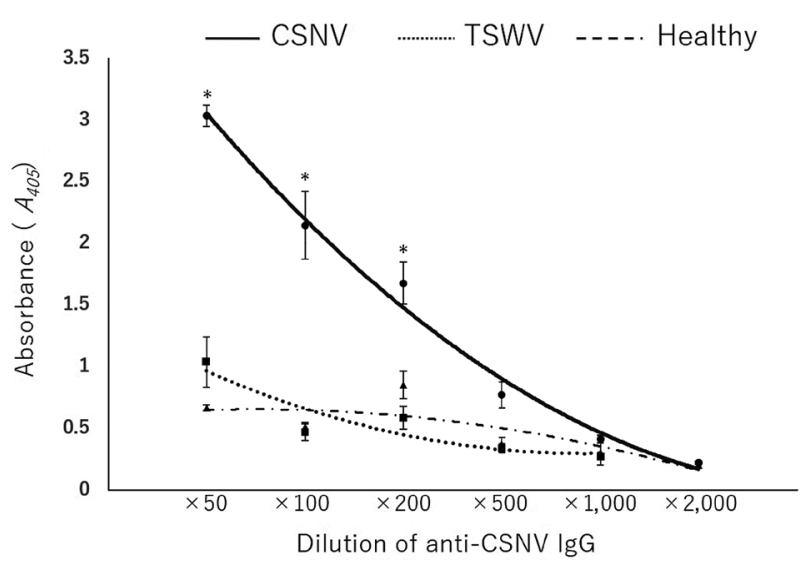

Fig. 2. Titer of the IgG for chrysanthemum stem necrosis orthotospovirus (CSNV)

CSNV-infected, tomato spotted wilt tospovirus (TSWV)-infected, and healthy plants (Nicotiana tabacum cv. Samsun) were used for this assay. Absorbance $\left(A_{405}\right)$ was measured $45 \mathrm{~min}$. after the addition of $p$-nitrophenyl phosphate. Asterisks indicate significant differences among the absorbance values of ELISA tests for CSNV-infected, TSWV-infected, and healthy plants (Tukey's HSD test, $P<0.05$ ). 

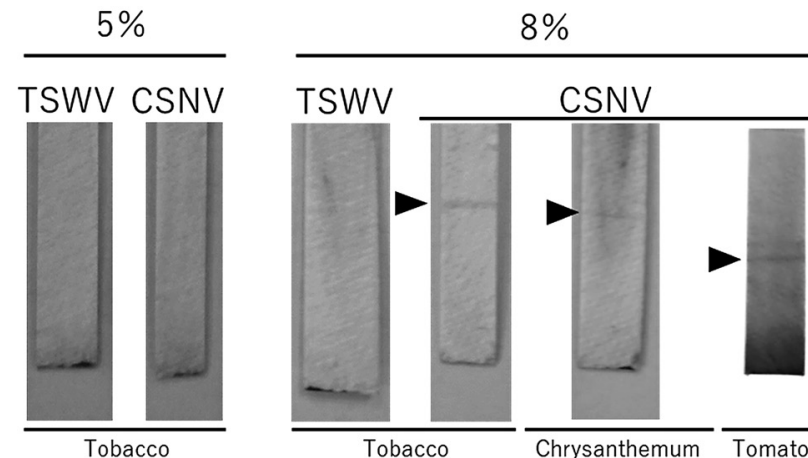

Fig. 3. Detection of chrysanthemum stem necrosis orthotospovirus (CSNV) from diseased plants (tobacco, chrysanthemum, and tomato) using rapid immunofilter paper assay (RIPA)

Note that $5 \%$ and $8 \%$ indicate the percentage concentrations of polystyrene (red colored) used for sensitization of the IgG antibody. Tomato spotted wilt tospovirus (TSWV) was used as a control. An arrowhead indicates the positive line for CSNV infection.

In this study, we obtained similar results showing that red particles at a concentration $8 \%$ but not $5 \%$ were suitable for RIPA in CSNV detection. These results suggest that the effect of the binding properties of the polystyrene particles to $\operatorname{IgG}$ rather than the titer of $\operatorname{IgG}$ plays an important role in detection by RIPA. However, further studies are needed to clarify this finding.

Orthotospoviruses are divided into two categories (New World and Old World) based on their origin (Mound \& Marullo 1996). Thus far, more than 30 orthotospovirus species have been reported in both the New World and Old World (Okuda 2016). Detection methods such as ELISA and RIPA using antibodies are still useful for the detection of plant viruses including orthotospoviruses, given their lower cost compared with other methods such as reverse transcription polymerase chain reaction. Moreover, RIPA offers the following advantages compared with the other methods: (1) requires no special equipment for detection, (2) enables on-site detection, and (3) entails less time for detection. Therefore, RIPA is very important for the diagnostics of orthotospoviruses. However, antibodies have only been produced for a few orthotospovirus species. Thus, the present study may prove helpful in the development of detection methods for orthotospovirus species.

\section{Acknowledgements}

The author wishes to thank Ms. Kazue Sato and Ms. Mariko Nagata for maintaining the plants and other materials. The author would also like to thank Dr. Jun Ohnishi for his helpful comments about the expression of foreign protein by the pMAL-c $5 \mathrm{x}$ vector.

\section{References}

Bezerra, I. C. et al. (1999) Increase of tospoviral diversity in Brazil with the identification of two new tospovirus species, one from chrysanthemum and one from zucchini. Phytopathology, 89, 823-830.

Clark, M. F. \& Adams, A. N. (1977) Characteristics of the Microplate Method of ELISA for the detection of Plant viruses. J. Gen. Virol., 34, 475-483.

Duarte, L. M. L. et al. (1995) Chrysanthemum stem necrosis caused by a possible novel tospovirus. J. Phytopathology, 143, 569-571.

Feldhoff, A. et al. (1997) Serological comparison of tospoviruses with polyclonal antibodies produced against the main structural proteins of tomato spotted wilt virus. Arch. Virol., 142, 781-793.

Fukami, M. et al. (2014) Detection of Chrysanthemum stem necrosis virus (CSNV) by Print-capture RT-PCR. Ann. Rep. Kanto-Tosan Pl. Prot. Soc., 61, 78-81 [In Japanese].

Gappa, R. \& Tsuda, S. (2015) Search for substitute particles for rapid immunofilter paper assay (RIPA) for detection of Melon yellow spot virus. Plant Protect., 69, 447-449 [In Japanese].

German, T. L. et al. (1992) Tospoviruses - diagnosis, molecularbiology, phylogeny, and vector relationships. Annu. Rev. Phytopathol., 30, 315-348.

Guan, C. D. et al. (1988) Vectors that facilitate the expression and purification of foreign peptides in Escherichia coli by fusion to maltose-binding protein. Gene, 67, 21-30.

Kuwabara, K. et al. (2010) Improved multiplex reverse transcription-polymerase chain reaction to detect and identify five tospovirus species simultaneously. J. Gen. Plant Pathol., 76, 273-277.

Kuwabara, K. \& Sakai, H. (2008) Tomato stem necrosis disease caused by Chrysanthemum stem necrosis virus (CSNV). Jpn. J. Phytopathol., 74, 225 [In Japanese].

Matsuura, S. et al. (2007) First report of Chrysanthemum stem necrosis virus on Chrysanthemums in Japan. Plant Dis., 91, 468.

Momonoi, K. et al. (2011) Stem necrosis of aster and Russell prairie gentian caused by Chrysanthemum stem necrosis virus. J. Gen. Plant Pathol., 77, 142-146.

Mound, L. A. \& Marullo, R. (1996) The Thrips of Central and South America: An Introduction. Memoirs on Entomology, International, 6, 1-488.

Ohki, S. (1997) Techniques and designs for plant virus identification. Japan Plant Protection Association, pp. 42-66.

Okuda, M. (2016) Tospoviruses occurring in and outside Japan. Jpn. J. Phytopathol., 82, 169-184.

Osaki, H. et al. (2011) Improved multiple rapid immunofilter paper assay to detect three viruses of cucumber simultaneously. J. Gen. Plant Pathol., 77, 307-311.

Tsuda, S. et al. (1992) A novel detection and identification technique for plant viruses: Rapid immunofilter paper assay (RIPA). Plant Dis., 76, 466-469.

Ullman, D. E. et al. (2002) Thrips as vectors of tospoviruses. Adv. Bot. Res., 36, 113-140.

Vaira, A. M. et al. (1996) A polyclonal antiserum against a recombinant viral protein combines specificity with versatility. J. Virol. Methods, 56, 209-219. 